\title{
Türkiye'de Çocukların Katılım Hakkı Üzerine Bir Derleme
}

\section{A Review on the Children's Right to Participant in Turkey}

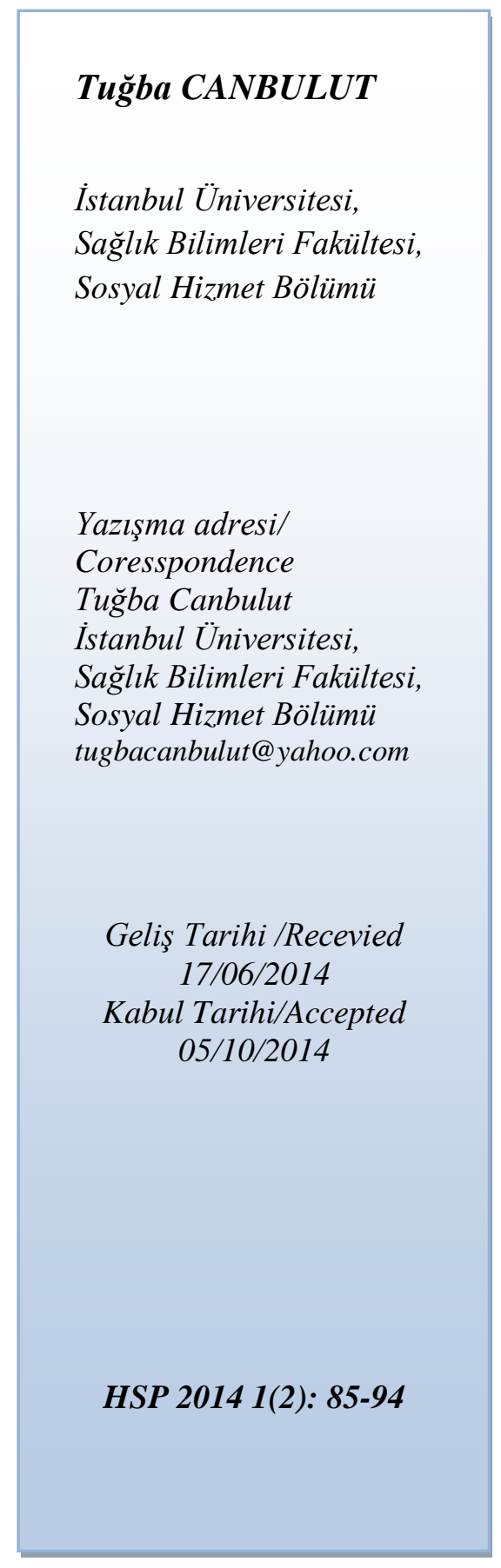

Özet

Türkiye'de çocuklar ve çocukluk sosyal bilim araştırmalarının önemli ve multidisipliner çalışma alanlarındandır. Çocukların katılım hakkı da çocukluk çalışmalarındaki önemli konulardan biridir. Türkiye'de çocukların katılım hakkı, yetişkinler tarafından çizilen sınırlarla ele alınmaktadır. $\mathrm{Bu}$ derlemede çocukların katılım sosyolojik bakış ile eleştirel bir şekilde değerlendirilecektir. Öncelikle Birleşmiş Milletler Çocuk Hakları Sözleşmesi'nde çocukların katılım hakkına dair belirlenen maddeler ele alınacaktır. Sonrasında, bu konuda -yetişkinler tarafindan oluşturulan- toplumsal değerlere dair bir tartışma yürütülecektir. Toplumsal değerler ise aile ve eğitim kurumlarının karşısına aile ve eğitim sistemi dışında kalanları koyarak ele alınacaktır. Bu şekilde, Türkiye'de çocukların katılım hakkına dair eleştirel bir bakışın gerekliliği savunulacaktır.

Anahtar Kelimeler: Çocuk hakları; çocukların katılım hakkı; birleşmiş milletler çocuk hakları sözleşmesi.

\begin{abstract}
The children and the childhood are one of the most important and multi-discipliner concepts of social sciences in Turkey. Children's rights to participation is also an important topic of childhood studies. In Turkey, children's rights to participant is handled with the limits that are defined by adults. In this review, children's rights to participant will be evaluated as critical in sociological view. At first, the children's rights to participant clauses of the United Nations Convention on Children's Rights will be handled. Then, a discussion in this topic -designed by adults- related to social values will be conducted. Social values are considered by crossing children outside of the family and the education system street culture and family\&education institutions. By this way, the necessity of need for a critical view on the children's rights to participant will be advocated.
\end{abstract}

Key Words: Children's rights; children's rights to participation; united nations convention on children's rights. 


\section{Giriş}

Ülkeler, eko-politik olarak geçirdikleri dönemlere göre incelendiklerinde, söz konusu dönemlerin sosyal konuları hakkında bilgi sahibi olmak da kolaylaşır. Ekonomik ve politik ve bir o kadar da kültürel duruşlar sosyal sermayeye yön vermektedir.

Şu durumda sosyal sermayeye konu olabilmek genel anlamda ülkelerin ekonomik, politik ve kültürel duruşları ve birikimleriyle alakalı görünmektedir. Çocukluk kavramı sosyal sermayenin bir ürünü olarak konuşulmaya başlandığından bu yana popülaritesini koruyan kavramlardan biridir.

Çocukluğun hiç tanınmadığı bir çağdan, hukuksal, toplumsal, eğitsel kurumlar içinde korunmaya alınan bir çocukluk kavramına geçiş tam dört yüzyıl sürmüştür. ${ }^{1}$ Artık çocuklar ve çocukluk hemen hemen her daim gündemde kalmayı başarabilen, üzerinde farklı disiplinlerden veya alanlardan neredeyse her yetişkinin konuşabildiği, dile pelesenk olmuş kavramlardandır. Söylenebilir ki çocukluk üzerine yorum yapabilmek yetkisi genel itibariyle cinsiyet, statü veya bakış açısı gözetmeksizin yetişkin olmakla kazanılmaktadır.

Sosyal bilimlerde çocukluk araştırmalarının tarihi çocuğa olan ilginin eksikliğiyle değil onların sessizliği üzerinden ele alınmaktadır. ${ }^{2}$ Çocukları oldukça seven, onları her zaman koruyan ve mutlaka gelecek vaat eden bireyler olmaları için uğraşan yetişkinlerin gözden kaçırdıkları çocukların kendi varlıkları üzerinde konuşabilmelerinin önüne koydukları yetişkince setler olduğu gerçeğidir. Sosyal bilimde de yetişkinlerin sınırlarıyla çizilmiş ve sosyal bir kurgudan ibaret bir çocukluk anlayışı hakimdir. Oysa çocuk eksik bir yetişkin olmadığı gibi kendine özgülüğü olan özel bir büyüme ve gelişme evresidir. ${ }^{3}$ Burada vurgulanmak istenen söz konusu evreyi belirleyenin, evreyi yaşayan çocuklardan ziyade onlar hakkında en doğru kararı verebileceklerinden hiç şüphesi olmayan yetişkin grubun olmasıdır.

$\mathrm{Bu}$ derleme, sosyal hizmet uygulamaları ve sosyolojik bakış kapsamında Türkiye'de çocukların ne tür bakış açılarıyla ele alındığını tartışmayı, çocukluk algısını mümkünse bir nebze sorgulamayı, çocukların toplumsal düzeyde kendileri adına konuşabilmelerinin olabilirliğini ya da olamazlı̆̆ını tartışmayı amaçlamaktadır. Sosyal hizmet alanının uygulamalarının değerlendirilmesinden öte sosyolojik çıkarımlar yapılması söz konusudur. Derlemenin akışı çocukların toplumsal hayattaki yerlerine göre belirlenmiştir. Yetişkin bakışının eleştirilmesinin yine yetişkinlerce belirlenen kavramsallaştırmalara göre yapılması bir ironi halini resmediyor olsa da, çocukluk tartışmalarının çocukların kendi hayatları için belirledikleri başlıklar kapsamında yapılabilmesinin önündeki engellerin kaldırılabilmesine dair umutvar durumun belirtilmesi gerekli görülmektedir. 


\section{Türkiye'de Çocuk Ve Çocukluk Kavramları Üzerine}

Çocuğun, toplumsal yaşamda nasıl anlamlandırıldığını araştırırken göz önünde bulundurulması gereken bir nokta çocukluk anlayışının, toplumsal dinamikler ve toplumsal yaşam koşullarını etkileyen toplumsal değişmeler doğrultusunda şekillenmekte olduğudur. ${ }^{4}$ Milli bir ülkenin bir olgu hakkındaki yorumuna bakarken milli kaynaklardan yararlanılabilir, zira bu kaynaklar milliliğin meşrulaştığı ideolojiyi ve dolayısıyla olgulara o ülkeyi oluşturan toplulukların bakış açılarını yansıtır. Türk Dil Kurumu da ülkenin millileşme politikalarının bir parçasıdır. Türk Dil Kurumu'nun çocuk kelimesi için yaptığı tanımlamalardan üç tanesi şöyledir: "bebeklik ile erginlik arasındaki gelişme döneminde bulunan oğlan veya kız, uşak", "büyüklere yakışmayacak, daha çok küçüklerin yapabileceği gibi davranan kimse” ve "belli bir işte yeteri kadar deneyimi ve yeteneği olmayan kimse". 5 Aslında bu tanımlamalar çocuğa bakışı net olarak anlatan tanımlardır.

Çocuk, bebeklik döneminin ardından girdiği gelişme döneminde büyük olmaya yetişkinliğe- hazırlanır, bu süre içinde birtakım tecrübeler edinir, bu tecrübeler doğrultusunda yetişkin yetenekleriyle donatılmış bir hayat kurar ver bu hayat içinde çocukluk döneminde yapılan bazı şeyleri tekrarladığında söz konusu -çocukluk- hali küçümsenir. Çocukluk dönemi, o dönemin niteliğinden değil, yetişkinlik döneminde doğabilecek aksaklıkların önüne geçilmesi adına çok iyi inşa edilmelidir. Erbay'a göre (6), yaşamdaki en temel değerlerin, tutumların, becerilerin ve yetişkinliklerin temeli çocukluk döneminde atılır. Bir başka deyişle, sonraki yaşamın yolu, çocukluk döneminde çizilir ve şekillenir. ${ }^{6}$ Yani yetişkinlikte hata veya aksaklık olarak görülen her türlü şeyde çocukluk döneminin payı olduğu hakim görüştür. Sağlam ve sağlıklı geçirilmiş bir çocukluk döneminden sonra gelen yetişkinliğin de aynı veya yakın koşullarda devam edeceği düşüncesi mevcuttur. Bu sebeple çocukluk önemlidir ve verimli geçirilmesi gereken bir süreci kapsamaktadır. Burada belki de göz ardı edilen durum şudur ki, hem çocukluk hem yetişkinlik dönemleri modern sosyal dünyanın birer tahayyülleridir. Ve bu tahayyüllerin kurgulanmasında sadece yetişkinlerin söz hakkının olması sorgulanması gereken bir durumdur.

Derleme, Türkiye'de çocuğun konuşulduğu bazı alanlarda çocuğun katılım hakkının ne derece göz önünde bulundurulduğuna odaklanarak devam edecektir.

Uluslararası belgeler, sözleşmeler insanlık tarihinin tutanak altına alınmış tanıklarıdır. ${ }^{7}$ Çocuk kavramının tartışıldığ yüzyı1, çocuklarla ilgili ulusal ve uluslararası düzenlemelere gidilen bir dönemi içermektedir. ${ }^{8}$

Yirminci yüzyılın ikinci yarısı, ‘çocuk sorunu'nun ağırlıkla tartışıldığı bir dönem olarak, çocuklarla ilgili tüm dünya ölçeğinde en önemli belge olan Çocuk Hakları Sözleşmesi 
(ÇHS)'nin ortaya çıkmasına olanak sağlamıştır. ${ }^{9}$ Bu sözleşmeyi son derece önemli kılan özelliği çocukluğun yansımalarını ve çocuk haklarını evrensel anlamda ele alıyor olmasıdır. $\mathrm{Bu}$ derleme kapsamında sözleşmenin değinilecek en önemli maddesi çocukların katılım haklarını tartışmaya en müsait maddelerden olan 12. maddedir.

Sözleşmenin 12. maddesine göre, taraf devletler, görüşlerini oluşturma yeteneğine sahip çocuğun kendini ilgilendiren her konuda görüşlerini serbestçe ifade etme hakkını bu görüşlere çocuğun yaşı ve olgunluk derecesine uygun olarak, gereken özen gösterilmek suretiyle tanırlar. ${ }^{10}$ Şüphesiz bu madde çocuğa, kendi hayatına dair fikir beyan etme hakkını yine yetişkinler tarafindan veren bir maddedir. Fakat Türkiye'de çocukların kendi kaderlerini tayin edebilme süreçlerine bakıldığında, aslında sözleşmeyle onaylanan bu hakkın 'çocukça' uygulanamazlığı dikkat çekmektedir. Toplumsal yapı kültürel normlar bir bütün olarak ele alınarak irdelendiğinde çocukların birer birey olarak görülemedikleri gerçeği açığa çıkmaktadır. Oysa sözleşmenin esas aldığı yaklaşım, yeni dünyanın nesne çocuktan özne çocuk anlayışına doğru evrilmesi yönündedir. ${ }^{11} \mathrm{Bu}$ bakışla çocukluk olgusuna yaklaşmanın çok da becerilebilen ve arzu edilen bir şey olmadığını Türkiye'de çocuk ekseninde yapılan çalışmalara bakarak anlamak mümkün olabilir.

$\mathrm{Bu}$ doğrultuda öncelikle değinilmesi gereken, çocukluğun da diğer bütün olgularda olduğu gibi bir sistem içinde ele alındığıdır. Türkiye'de çocuk eksenli çalışmalar genel anlamda, iki yana yaslanmış durumdadır.

Çocuklar bir tarafta düzenli hayatlarının içinde mensubu oldukları aileler ve eğitim sistemine göre değerlendirilmekte, diğer taraftan düzensiz asi hayatlarının içinden 'kurtarılmaya' uğraşılırken ele alınmaktadırlar. Bu bağlamda çocuğun katılım hakkını tartışmak için iki önemli başlık belirlenebilir. Bunlardan biri toplumsal düzenin sürdürülebilir halini destekleyen aile ve eğitim kurumları iken, diğeri, toplumsal düzenin aksamasına neden olan aile ve eğitim sistemi dışında tutulan çocuklara dair kültürdür. Bu başlıklar derleme kapsamında tartışılmak istenen konunun daraltılabilmesi açısından seçilmiş olmakla birlikte, belirlenen başlıklar dışındaki konuların ayrıca ele alınması gerekliliği de vurgulanmalıdır.

\section{Aile Ve Eğitim Kurumları Bağlamında Çocuğun Katılım Hakkı}

Aile, toplumun düzen halinin devamlı kılınabilmesi adına işleyen bir kurum olma boyutuyla sadece işleviyle- ele alınıp, geleneksel kültürel yapısı bir kenara bırakıldığında ancak kutsal yapısı sorgulanabilir hale gelebilen bir ortam olur. Aile, kadınları, erkekleri, çocukları, gençleri, yaşlıları, engellileri ve böyle kategorize edilen bütün insanları birey olma 
Kimliklerinden arındırarak her birine verdiği toplumsal rollerle onları bir bütün halinde gösteren bir kurumdur. Aileye bu gözle bakmak aslında Derridavari bir yapıbozum yapmaktır. Yazının eleştirel ruhu ve tartışma ortamının yaratılabilmesi adına kutsanmış aile formatının sorgulanması söz konusudur ki böylece aile yapısallığının yok ettiği birey çocuk veya çocuğun özne olması durumları ile katılım hakkı tartışılabilsin.

Aile, çıkarların bir dayanışmasıdır. ${ }^{12}$ Aile yanında düzenli hayatın birer parçası olan çocuk bireyler, aileye ait demografik bilgilerin ve çıkar dayanışmasının da bir bölümünü oluşturmaktadır. 'Bakmakla yükümlü olunan çocuk' olarak bir nicel ifadeye bürünmektedirler.

Bir diğer taraftan çocuk ailenin demokrasi yoksunu üyelerinden biri olarak aileyi ilgilendiren konuda sadece üstüne düşeni yapmakla yükümlü iken, kendisiyle alakalı konulardaki söz hakkı da son derece azdır. Öyle ki çocuğun aile içinde yer alması, zaten onun için olabilecek en muntazam durumdur.

Çocuğun katılım hakkından bahsederken değinilmesi gereken önemli noktalardan biri çocuğun kimlerle veya ne şekilde zikredildiğidir. Türkiye'de çocuk kelimesinin anıldı̆̆ yerlerden bazılarını söylemek gerekirse (bu bölümde aile vurgusuna dikkat çekilmeye çalışılmaktadır), çok çocuklu aileler, tek çocuklu aileler, tek ebeveynli çocuklar, boşanmış ebeveynlerin çocukları, çocuksuz aileler ilk akla gelenler olmaktadır. Görüldüğü gibi, ailenin, çocuğun konuşulmasındaki yeri ve önemi yadsınamayacak derecededir.

Çocuklar daha önce de bahsedildiği üzere eksik yetişkinliklerinden(!) tam yetişkinlik sürecine yönelik hazırlanan ve bu uğurda özne olma hallerinden bertaraf edilen bireylerdir. Her çocuk onu yetiştirenlere ve çevresine hatta aynı toprağı paylaştığı insanlara karşı hayırlı bir evlat olmak üzere hayata hazırlanma yolundadır. Hayırlı evlat mitine göre, çocukların 'büyüdüklerinde' onlara sağlanabilen veya sağlanamayan refahın karşılığını pozitif yönde vermeleri gerekmektedir. Çocuklar birer yetişkin olduklarında ailelerinin hayatlarını idame ettirmelerine yardımcı olacak birer yatırım gibi algılanmaktadırlar. Bu algıyı biraz detaylı tartışmak gerekirse çocukların birinci olarak işçi tanımlamasıyla toplumsal alanda yer almalarından, ikinci olarak ise yetişkinlerin sahip oldukları birer nesne olmalarından bahsedilebilir.

(Çocuk işçiliği anlamında) Çocuk emeği, bir taraftan nicelik ve nitelik açısından dönemden döneme, toplumdan topluma farklılık gösterirken, diğer taraftan buna yüklenen anlam da değişebilmektedir. ${ }^{13}$ Türkiye'de de çalışan bir çocuk olmak, yaşanılan bölgenin kültürüne göre farklı anlamlar kazanabilmektedir. Kırsal alan çocuk işçiliğinin masumane 
alanı olurken kentsel alanda çalışan çocuğun her şeyden önce yoksul stigması ön plana çıkabilmektedir.

Çocukları çalışmaya iten çeşitli nedenler bulunmaktadır ancak temelde bilinmesi gereken nokta, çocuğu çalışmaya iten nedenlerin onun dışındaki faktörlerden ileri geldiğidir. ${ }^{6}$

Çocukların yatırım gibi görülmelerindeki ikinci nokta ise 'çocuk sahibi olma' sorunsalıdır. Bir metaya sahip olmak gibi dünyaya gelmesine vesile olduğu için bir çocuğa sahip olma isteği de çocuğun katılım hakkı bünyesinde eleştiriye açık olması gereken bir nokta olarak görülmektedir. Çocuk Hakları Sözleşmesince 18 olarak maksimize edilen çocukluk yaşı, 'çocuk sahibi' ailelerce daha da artırılabilmektedir. 'Ailenin gözünde (hala) çocuk olmak' çocuğun aile tarafından korunmasını sağlayan bir mittir. Bu koruma karar aşamalarını da aileye devretmektedir. Karar verme mekanizması olarak aile büyüklerinin etkin role sahip olmaları kültürel arka planının yanısıra, aileyi korumayı görev edinen devletin de önemli bir sosyal politikasıdır. Çünkü iyi tasarlanmış bir çocukluk ve aile kurgusu ile bireylerin kontrol edilebilmeleri son derece kolaylaşabilmektedir.

\section{Eğitim Sisteminde Çocuğun Katılım Hakkı}

Eğitim sisteminde çocukların konuşulması ve katılım hakkına bakıldığında aileden farklı bir tablo ile karşılaşıldığı söylenemez. Çocuklar, tümüyle hizmet bekleyen bireyler olarak görülmektedir. ${ }^{14} \mathrm{Bu}$ da onları katılım hakkı açısından pasifize etmektedir. Bu işlemde eğitimin payı büyüktür.

Çağdaş kapitalist toplumda eğitim ve öğretim sermaye artışının ve kapitalist toplumun devamının bağlı olduğu tek meta olan -toplumsal emek gücü üretiminde- önemli bir rol oynar. ${ }^{15}$ Marksizmin sık sık vurgu yaptığı gibi emek gücü üreten bir eğitim sistemi mevcuttur. Bunu yaparken de çocukluğu, çocukların karar vermediği bir sistemin içinde yoğurur. Eğitim sisteminin parçası olduklarında zaten hayatın bir çok alanından soyutlanan ve işleri onlara tanınan imkanlarla eğitim sisteminin daha efektif birer parçası olmak şeklinde kısıtlanan çocuklar söz konusudur. Foucault'ya dem vurarak söylemek gerekir ki okullar veya okullaştırılan kurs ve benzeri kurum ve kuruluşlar çocukların hapsedilme yerleri gibidir. Okulun çocuklara kendi yaşıtları ile sosyalleşmesi için tanıdığı varsayılan olanağı tersten okumakta fayda görülmektedir. Şöyle ki okul/eğitim sisteminin içindeki çocuk öznesi diğer toplumsal olayların tamamen dişında ve kontrol altında tutulmaktadır.

Devlet tarafından uygulanan eğitim politikaları, genel olarak çocukların katılım ve gelişim hakkı ile ters düşmekle birlikte, özellikle katılım hakkı ile ters düşen uygulamaların 
yürürlüğe konulması ve kurumsallaştırılması ile sonuçlanmıştır. ${ }^{14}$ Müfredatla yoğun bir ilişki içinde geçen ve toplumsal kararlarda yok sayılabilen çocuklar söz konusudur ki bu çocuklar bir çocukluk kurgusu içinde toplumsal olaylardan dişlanmaya maruz kalan çocuklardır.

Eğitim sisteminin önemli bir parçası da millileştirme politikalarına çocukları dahil eden bazı eylemleri içeriyor olmasıdır. Çünkü devlet çocuk sadece ailesinin değil aynı zamanda devletinin de geleceği için önemli görülmektedir. Millileştirme politikalarıyla çocuğa yüklenen gelecek kaygısının yanında bir de geçmişin sorumluluğu vardır.

(Oysa) çocuk geçmişle ilgilenmez, o şimdi'dir ve tereddütsüz biçimde hayatla ilişki içindedir. ${ }^{3}$ Eğitim sistemiyle çocuğun şimdisi elinden alınmakta, geçmişin geleceğe yansıması olarak çocuk kullanılmaktadır.

\section{Aile ve Eğitim Kurumları Sisteminin Dışındaki Çocukların Katılım Hakkı}

Yazının akışı doğrultusunda aile ve eğitim kurumlarında çocukluk kurgusuna değinildikten sonra, şimdi de bu sistemlere toplumsal düzeni stabil kılabilecek şekilde dahil olamayan çocuklara odaklanmakta fayda vardır. Onlar da, bu sistem dış1lıklarıyla yine yetişkinlerce tanımlanmış hayatlar yaşamaktadırlar. Aile yanında olmayıp, topluma zarar veren, aynı zamanda kendileri tehlike altında olduklarından bir şekilde gözetim altında tutulmak istenen çocuklar ile aile yanında oldukları için zarar gören ve gördükleri zararı topluma yansıtma riski gösteren çocuklar düzensiz gruba mensupturlar ve o çocuklar üzerinde yoğunlaşan çalışmalar bir hayli fazladır. Aslında denilebilir ki kendilerini aile kurumundan dışarı çıkaran çocuklar daha çok konuşulmaktadır. Çünkü diğerleri zaten kendilerine yetişkinlerce sağlanan sistemin birer parçası halinde sorunsuz ilerlemektedir. Aile yoksa ya da varken yokmuş gibiyse çocuk o zaman yetişkinlerin dikkatini daha çok çekmektedir. Sokak çocukları çalışmaları bunun en iyi örneğidir.

Damga kuramının sosyolojideki öncüsü kabul edilen Erving Goffman damgayı 'sahip olunan nitelikler ve toplumda kabul edilmiş değerler arasındaki ilişki biçimi' olarak tanımlar. ${ }^{16}$ Sokakta yaşayan veya çalışan çocukların sokak çocuğu damgası da toplumun değer yargılarından yola çıkılarak oluşturulmuş bir kurgudur. Söz konusu 'damga' sokaktaki çocuğun sistem dışılığına vurgu yaparak onu da sisteme dahil etme çabalarını meşrulaştırmaya imkan sağlamaktadır. Modern devletin toplum düzeninin sağlanması, çocuğun sokakla/sokakta kurduğu ilişkinin çocukluk değerlerinin üstündedir.

\section{Sonuç}


Devletin sosyal politikalar kapsamında üzerinde çalışmalar yaptığı konular aslında birer bireydir. Kadınlar, çocuklar, engelliler gibi sosyal politikaya dâhil edilip sosyal hizmet uygulanan kişilerin bu hizmetlerden memnuniyetini ölçen de yine devletin ta kendisidir. Çünkü memnun olmak için alınacak referans sistemi de modern devlet tarafindan kurgulanmaktadır.

Katılım, karar süreçlerinde ve etkinliklerde yer almak ve etkili olmaktır; karar mekanizmalarında, uygulama ve değerlendirme süreçlerinde aktif müdahalede bulunmaktır. ${ }^{17}$ $\mathrm{Bu}$ derlemede, çocukların kendi hayatları üzerinde konuşabilmeleri ve bu konuşmayı yaparken ebeveyn ya da toplum baskısı altında kalmamaları gerekliliği üzerinde durulmaya çalışılmıştır. Çocukların psiko-motor gelişimleri tamamlanmadan bu sürece nasıl hâkim olacakları sorusu bir karmaşaya yol açmış olabilir. Fakat burada bahsedilen "bırakınız yapsınlar bırakınız geçsinler” gibi bir yaklaşım değildir. Erkekler için gelişmiş yaşam şartları nasıl hazırlanabiliyorsa, kadınlar bu haklarını elde etmek için nasıl savaşıyorsa çocukların da bütün bunları yapabilmelerine imkân verilmesi gerekliliği, çocukların sahip olunan değerler olarak düşünülmemesi, değerli ve yatırım yapılması kişiler gibi algılanmaması vurgulanmak istenen noktadir.

Çocukların çocuk olma hallerinin kendilerince sorgulanması Türkiye'de oluşabilecek radikal olaylardan biri olarak görülebilir, böyle bakıldığında çocuğa bakışın değiştirilmesi çok uzak gibidir. Fakat uzak olduğunu düşünmek bile çocuklar adına verilmiş bir karardır. Tam da bu yüzden Şirin'in (18) de bahsettiği gibi çocukluğun yitip gitmesine karşı yeni bir çocuk okumasinın yapılması gerekmektedir.

\section{Kaynaklar}

1. Bekir O. Toplumsal Tarihte Çocuk Sempozyum 23-24 Nisan 1993 [Children in Social History Symposium April 23 to 24 1993]. İstanbul: Tarih Vakfi Yurt Yayınları; 2013. p. Giriş xi-xii.

2. Prout A, James A. A New Paradigm fort he Sociology of Childhood Provenance, Promise and Problems.In: Prout A, James A, editors. Consturcting and Reconstructing Childhood: Contemporary Issues in the Sociological Study of Childhood. Second Edition. London: Falmer Press; 1997. p. 7-33.

3. Şirin M.R. Dersimiz Çocuk Çocuk Üzerine Düşünce Yazıları [Study Children, Thoughts Writing on Children]. İstanbul: İz Yayınc1lı; 2012. p. 32.

4. Tunca T. Türkiye'de Değişen Aile ve Çocuğa Yüklenen Anlamlar [The Changing Meaning of Family and Children in Turkey]. In: Adak N, editors. Değişen Topluma Değişen Aile Sosyolojik Tartışmalar [Changing Family in Changing Sociological Society Debates]. Ankara: Siyasal Kitabevi; 2012. p.163-176. 
5. Türk Dil Kurumu, Türk Dil Kurumu Genel Sözlük. 2012. [cited 2012 June]. Available from: http://www.tdk.gov.tr/index.php?option=com_gts\&arama=gts\&guid=TDK.GTS.4fddeb42 0d9bb4.36007244.

6. Erbay E. Çocuk İşçi Olmak: Çocuk İşçiliğine Retrospektif Bir Bakış [Becoming Child Labour: A Retrospective Look at Child Labour]. Ankara: Sosyal Hizmet Uzmanlar1 Derneği Yayını; 2008.

7. Yelken R. Çocuk Suçluluğunun Önlenmesinde Merkezi Kuram Aile: Çocuklara Dair Uluslar arası Sözleşmelerin Analizi [Center Theories for Prevention of Child Criminality: Analysis of the International Convention Relating to Children]. In: Hançerli S, Sevinç B, Gürer C, Öner M. C, editors. Suça Sürüklenen ve Mağdur Çocuklar [Crime dragged Children and Child Victims]. Ankara: SABEV Yayınlar1; 2011. p.32-41.

8. Baykara Acar Y. İstisnai Öyküler Cinsel Suçtan Hükümlü Çocukların Yaşam Öyküleri [Exceptional Stories Convicted of sexual crimes Children's Life Stories]. Ankara: Maya Akademi; 2011.

9. Yolcuoğlu İ.G. Ebeveyn Bakımından Yoksun Çocuklar ve Sosyal Hizmet [Children Deprived of Parental Care and Social Work]. In: Acar H, Negiz N, Akman E, editors. Sosyal Politika ve Kamu Bileşenleriyle Sosyal Hizmet Temelleri ve Uygulama Alanları. Ankara: Maya Akademi; 2013. p.155-167.

10. UNICEF. 2014. [cited 2014 June]. Available from: http://www.unicef.org/turkey/crc/_cr23c.html.

11. TBMM. 2014. [cited 2014 June]. Available from: http://tbmm.gov.tr/komisyon/insanhaklari/pdf01/137-160.pdf.

12. Güçlü S. Aileye İlişkin Kuramsal Yaklaşımlar [Theoretical Perspectives on Family]. In: Adak N, editors. Değişen Toplumda Değişen Aile Sosyolojik Tartışmalar [Changing Family in Changing Sociological Society Debates]. Ankara: Siyasal Kitabevi; 2012. p.6591

13. Makal A. Çocuktum Ufacıktım Türkiye'de 1920-1960 Döneminde Çocuk İşçiliği [Child Labour in Turkey 1920-1960 Period]. Ankara Üniversitesi Siyasal Bilgiler Fakültesi Gelişme ve Toplum Araştırmaları Merkezi (GETA) Tartışma Metinleri No.98. Ankara: 2006.

14. Değirmencioğlu S. M. Tersten Katılım: Katılım Hakkı Üzerine Bir Değerlendirme [Reverse Participation: An Evaluation of Participation Rights]. In: Acar H, İçağasığlu Çoban A, editors.Birleşmiş Milletler Çocuk Haklarına Dair Sözleşmenin 20. Yılında Türkiye'de Çocuk Hakları [United Nations Convention on the Rights of the Child on the 20th anniversary of Children's Rights in Turkey]. Ankara: Maya Akademi; 2010. p.119128.

15. Rikowski G. Marksist Eğitim Kuramı ve Radikal Pedagoji [Marxist Educational Theory and Radical Pedagogy]. İstanbul: Kalkedon Yayınları; 2011.

16. Gürdal Ünal A. Türk Çocuk Edebiyatında Engellilik 1969-2009 [Disability in Children's Literature in Turkey 1969-2009]. İstanbul: Evrensel Basım Yayın; 2011.

17. Değirmencioğlu S. M. Çocuklar ve Gençlerin Gözünden Katılım [Participation Through the Eyes of Children and Youth]. In: Acar $\mathrm{H}$ and others, editors. 6. Ulusal Sosyal Hizmetler Konferansı Küreselleşme, Sosyal Adalet ve Sosyal Hizmetler [6th National 
Social Services Conference Globalization, Social Justice and Social Services]. Ankara: Sosyal Hizmet Uzmanları Derneği Genel Merkezi Yayını; 2005. p. 311-316.

18. Şirin M. R. Gösteri Çağı Çocukları İletişim Toplumunda Medya Sarmalı [Show Age Children Spiral Media in Society]. İstanbul: İz Yayıncılık; 2006. 